\title{
A CONFIGURAÇÃO DE IMAGENS DOS GESTORES SOBRE ESTRATÉGIA ORGANIZACIONAL
}

\author{
The managers images configuration on organizational strategy
}

\author{
Gabriel Sperandio Milan ${ }^{\mathrm{a}}$, Deonir de Toni ${ }^{\mathrm{b}}$ \\ a Administrador de Empresas, Dr. Prof. e Pesquisador da Universidade de Caxias do Sul, UCS, Caxias do Sul, RS - Brasil, \\ e-mail: gsmilan@ucs.br \\ b Administrador, Dr. Prof. e Pesquisador da Universidade de Caxias do Sul, UCS, Bento Gonçalves, RS - Brasil, \\ e-mail:deonirdt@terra.com.br
}

\begin{abstract}
Resumo
A forma como os gestores definem e implementam estratégias também depende das imagens que eles possuem quanto ao conceito de estratégia. Sendo assim, este trabalho tem como objetivo identificar as imagens de estratégia organizacional, sob a ótica dos gestores. Entende-se que as imagens estão organizadas como uma rede de significados ou esquemas associados e organizadas em torno de alguns elementos centrais, que são socialmente aceitos e compartilhados. A identificação das imagens mentais que os gestores têm a respeito de estratégia organizacional é relevante para aprofundar a compreensão das práticas organizacionais adotadas em um determinado ambiente competitivo. A partir das cinco dimensões propostas por Mintzberg (1987) e do Método de Configuração da Imagem (MCI), um instrumento de pesquisa já testado e validado na identificação das imagens de organizações, produtos, serviços e marcas, procurou-se identificar, em uma amostra de 46 gestores, qual sua imagem coletiva de estratégia organizacional. Os resultados deste estudo relatam a primeira exploração para propor a Técnica de Configuração de Imagens Ideativas (TCID), instrumento de suporte à consultoria buscando a qualificação da gestão empresarial.
\end{abstract}

Palavras-chave: Configuração de imagens; Estratégia; Imagens.

\begin{abstract}
The way managers define and implement strategies also depends on the image they have of strategy concept. Therefore, this work aims at identifying the images of organizational strategy from managers' prospect. Images are understood as being organized as a net of meanings or schemes, which are arranged around a few central elements, socially accepted and shared. Identifying the mental image that managers have regarding organizational strategy is relevant
\end{abstract}


to deepen understanding of organizational practices adopted by a certain competitive environment. Starting from five dimensions proposed by Mintzberg (1987) and from the Método de Configuração da Imagem (MCI), an already tested and validated research instrument for identification of images in organizations, products, services and brands, we tried to identify, within a sample of 46 managers, what the collective of organizational strategy is. The outcomes of this study relate the first exploration to propose the Técnica de Configuração de Imagens Ideativas (TCID), an instrument to help audits, seeking the qualification of entrepreneurial management.

Keywords: Images configuration; Strategy; Images.

\section{INTRODUÇÃO}

As imagens mentais que se configuram a partir da percepção de cada indivíduo constituem o elemento cognitivo básico do pensamento humano, sendo responsáveis pelo direcionamento do comportamento das pessoas. Sabe-se que as impressões e as convicções, ou seja, a forma como o homem vê e interpreta o mundo, são os pressupostos básicos que influenciam o seu comportamento. A compreensão de como os principais gestores das empresas percebem a estratégia organizacional pode ajudar a entender como esses responsáveis pelo direcionamento de estratégias desdobram sua visão em ações, atitudes e comportamentos, contribuindo assim, para melhor prever os pressupostos que conduzem a competição dentro de determinada indústria ou ambiente competitivo.

Muitas das ações estratégicas das organizações são direcionadas pelas imagens mentais que seus dirigentes fazem da conjuntura geral de seus negócios e do que seja o comportamento estratégico. No entanto, identificar formas de mensurar os modelos mentais, desponta como um desafio para muitos pesquisadores. Com a preocupação de apresentar uma proposta de mensuração e configuração das imagens, este trabalho tem o objetivo de identificar a imagem coletiva que alguns gestores de empresas da região da Serra Gaúcha têm em relação à estratégia organizacional, categorizando os atributos desta imagem a partir das cinco dimensões de estratégia propostas por Mintzberg (1987), conhecida como os 5 Ps: Plano, Pretexto, Padrão, Posição e Perspectiva, os quais serão abordados na próxima seção.
Neste contexto, foi definida a seguinte questão central de pesquisa: qual imagem de estratégia organizacional emerge da ótica dos profissionais ligados à gestão empresarial, na região da Serra Gaúcha? Com este propósito foram adaptadas, principalmente, a Técnica de Configuração de Imagem de Produto (TCIP), desenvolvida e evoluída por Schuler (2004) e De Toni (2005), e a Técnica de Configuração de Imagem de Serviços (TCIS), implementada por De Toni, Milan e Schuler (2005), para constituir uma nova aplicação para o método, o de configurar imagens ligadas aidéias, ou seja, imagens ideativas. Para tanto, na abordagem de campo, com caráter exploratório, foi abordado um grupo de 46 gestores, procedendo-se a um levantamento de suas percepções em torno do tema da pesquisa.

O termo Estratégia Organizacional é freqüentemente empregado no cotidiano das empresas. Há, porém, uma carência de reflexão sobre a sua definição e melhores desdobramentos, o que pode contribuir para torná-lo difuso e impreciso para grande parte dos gestores (FONSECA; MACHADO-DA-SILVA, 2001). Com o nível acirrado de concorrência existente no mercado, entretanto, as empresas devem intensificar a busca de qualificação para a adoção de estratégias mais efetivas, no sentido de estabelecer e consolidar uma vantagem competitiva sustentável, conferindo-lhes uma capacidade competitiva mais consistente e duradoura (PORTER, 1985,1996; ROWE; BARNES, 1998). Essa qualificação está diretamente relacionada à forma pela qual os gestores entendem e aplicam o seu conceito de estratégia organizacional em suas empresas. Sendo assim, torna-se útil a 
análise de como a estratégia organizacional é compreendida pelos mesmos e se o Mapa de Configuração de Imagem (MCI) pode apresentar-se como um instrumento adequado para cumprir com essa finalidade. O MCI compõe-se de um conjunto de técnicas para explorar as imagens mentais de um determinado público, sobre algum objeto, compondo-se de técnicas específicas tais quais a TCIP (Técnica de Configuração de Imagem de Produto),a TCIS (Técnica de Configuração de Imagem de Serviço), a TCIO (Técnica de Configuração de Imagem Organizacional) e a TCIM (Técnica de Configuração de Imagem de Marca).

\section{REVISÃO DA LITERATURA}

\section{Organização das imagens na memória}

Dentre as diferentes perspectivas do entendimento de como as imagens estão organizadas na memória de um indivíduo, duas teorias merecem destaque: a Teoria das Representações Sociais (TRS) e a Teoria do Núcleo Central. A TRS, inicialmente abordada por Moscovici (1978), é uma das principais teorias que explicam os processos de influências sociais e como os indivíduos adquirem e organizam seus modelos mentais (BREAKWELL, 2001). Apresenta a formação dos modelos mentais como um processo socialmente mediado. Assim, o grupo de pessoas e seu comportamento, o contexto organizacional e os canais de informação são agentes fortemente influenciadores na formação das imagens dos indivíduos.

Para Moscovici (2000), as representações sociais são um conjunto de convicções, crenças e valores amplamente compartilhados pelas pessoas, que têm como finalidade tornar os eventos familiares, assegurando a possibilidade de compartilhamento da rede de significados que lhes forem atribuídos.

A TRS sugere que os modelos mentais de qualquer objeto ou fenômeno será determinado pela inclinação do indivíduo para uma forma particular de ancoragem e objetivação. É importante ter em mente que estes dois processos envolvem uma interação social e o estabelecimento de significados compartilhados e do consenso por meio da comunicação entre as pessoas (BREAKWELL, 2001). Dessa forma, se os modelos mentais de estratégia organizacional são gerados através de um processo de representação social, eles serão substancialmente compartilhados pelos membros de uma subcultura discreta, particular. Isso não significa que todos os membros de uma subcultura tenham um modelo mental idêntico de estratégia organizacional, mas seus integrantes compartilham certos elementos comuns. Estes elementos comuns estão contidos no núcleo de suas representações, enquanto os elementos particularizados estão localizados nas periferias das representações do grupo.

A Teoria do Núcleo Central, por sua vez, sugere que o homem organiza e processa as informações de forma dinâmica e evolutiva em torno de um Núcleo Central e de um conjunto de elementos periféricos (ABRIC, 1984, 1993; SÁ, 1996). Segundo o pesquisador francês Jean-Claude Abric (1984), toda e qualquer representação é organizada em torno de um Núcleo Central, constituído de um ou mais elementos que dão, à representação, o seu significado, e que ocupam, na estrutura dessa representação, uma posição privilegiada.

O Núcleo Central é determinado, em parte, pela natureza do objeto representado e, em parte, pela relação que o sujeito, ou um grupo de pessoas, mantém com este objeto. Dessa forma, o Núcleo Central se constitui como um subconjunto da representação, composto de um ou mais elementos, cuja ausência desestruturaria a representação ou lhe daria uma significação completamente diferente (SÁ, 1996).

Os atributos que compõem o Núcleo Central são marcados pela memória coletiva, e são estáveis e resistentes a mudança. Sua função é gerar significação para as imagens. Em torno do sistema central da imagem há o sistema periférico, constituído pelos atributos mais flexíveis, sensíveis ao contexto imediato. Sua função é permitir a adaptação à realidade, bem como a diferenciação do conteúdo e a proteção ao sistema central. Os sistemas periféricos estão mais próximos das práticas do cotidiano e sujeitos as mudanças (SÁ, 1996).

Portanto, entende-se que as imagens estão organizadas como uma rede de significados ou esquemas associados e organizadas em torno de alguns elementos centrais que são socialmente aceitos e compartilhados. Mais especificamente, o 
uso das imagens mentais que os gestores têm de estratégia organizacional é muito proveitoso para explicar conceitualmente a maneira como a configuração de sua realidade organizacional é estruturada, bem como para compreender melhor as estratégias e as práticas organizacionais adotadas.

\section{Definindo estratégia organizacional e explorando suas dimensões - os 5 Os}

Pode-se pensar em estratégia organizacional como a busca por uma posição competitiva favorável ou ideal, caracterizada pela criação de uma posição exclusiva e valiosa, efetuando tradeoffs claros (PORTER, 1985, 2001). Nesse processo, é recomendado que os gestores reflitam se suas decisões contribuem para a geração de valor de seus clientes, se estão fundamentadas em competências e recursos singulares e se há riscos iminentes e reais destes recursos e competências a serem imitados ou substituídos pela concorrência (HOOLEY; SAUNDERS; PIERCY, 2005). Do mesmo modo, fortalecer a cadeia de valor do negócio, maximizando a performance em cada área, processo e atividade da empresa, integrando fornecedores, clientes e demais stakeholders em torno de objetivos comuns é apontado como imprescindível para o sucesso (PORTER, 1985).

Para Porter (1996), como a estratégia se baseia em atividades únicas, singulares a uma determinada empresa, a definição de estratégia está relacionada a ser diferente. Significa escolher deliberadamente um conjunto de atividades diferenciadas para possibilitar a geração e entrega de um mix único de valor aos clientes.

Para Eisenhardt (1999), estratégia é o processo de tomada de decisão da empresa, reforçado pela sua intuição coletiva. Já para Quinn (1980), a estratégia é o padrão ou o plano que integra objetivos e metas, políticas e uma seqüência de ações coerentes com a estrutura e recursos da empresa. Jain (2000) considera estratégia como o padrão de políticas e planos para alcançar objetivos e metas, levando em conta o negócio no qual a companhia está, ou busca estar, e o tipo de empresa que ela é, ou busca ser.

De acordo com Thompson Jr. e Strickland III (2000), a estratégia consiste de um conjunto de mudanças competitivas e abordagens comerciais focadas na melhoria do desempenho organizacional. Em outras palavras, é o desenvolvimento e implementação de um planejamento capaz de reforçar a posição mercadológica da empresa. Consoante isso, Matsuno e Mentzer (2000) afirmam que uma empresa escolhe sua estratégia com base no entendimento do ambiente, o que direciona a atenção da empresa para determinadas dimensões de performance nas quais ela busca se destacar.

Considerando a complexidade intrínseca à definição de estratégia, entende-se que Mintzberg (1987), ao defender a possibilidade de conceituá-la a partir de cinco dimensões, os 5 Ps da estratégia, trouxe uma visão menos cartesiana para a academia, sem a necessidade de haver uma única definição, "a definição correta". De acordo com Mintzberg (1987), pela sua natureza, a estratégia implica em uma série de significados ou dimensões. Neste sentido, a estratégia pode ser compreendida como um(a):

a) Plano (Plan): equivale a dizer que estratégia é um curso de ação, uma diretriz para lidar com uma situação. Nesta dimensão, a estratégia tem duas características essenciais: é elaborada de forma anterior à implementação das ações, e desenvolvida de forma consciente e, na maioria das vezes, explicitada através de um planejamento formal. Assim, a estratégia pode ser vista como um plano que especifica quais escolhas e caminhos serão necessários, desenhado para assegurar que os objetivos básicos do negócio sejam alcançados;

b) Pretexto (Ploy): nesta dimensão, a estratégia se constitui em uma manobra específica, um truque ou estratagema, com a intenção de obter vantagem sobre um concorrente ou competidor. Por exemplo, uma corporação pode ameaçar expandir sua capacidade instalada apenas para desencorajar um competidor a construir uma nova planta. A estratégia como pretexto foca sua atenção no aspecto dinâmico e competitivo entre as organizações que disputam o mercado; 
c) Padrão (Pattern): foca na ação e indica a(s) estratégia(s) realizada(s). Como um fluxo de ações, indica a consistência no comportamento adotado ou no padrão que caracteriza uma corrente de ações;

d) Posição (Position): indica o lugar no ambiente onde se concentram os recursos. É uma idéia que inclui as escolhas dos segmentos e nichos, ou a posição ocupada no mercado para evitar os competidores ou ser melhor do que eles. É uma maneira de contextualizar a empresa inserindo-a em seu ambiente competitivo;

e) Perspectiva (Perspective): consiste não apenas de uma posição escolhida, desejada, sob uma perspectiva de longo prazo, mas também em uma forma dos gestores e da organização, como um todo, enxergarem o mundo e avaliarem as possibilidades da empresa perante $\mathrm{o}$ mercado. Assim, algumas organizações são mais agressivas, buscando novas tecnologias e novos mercados, enquanto outras percebem o mundo como mais estável, buscando criar barreiras para se proteger da concorrência e/ou de outras ameaças potencias. A estratégia, como perspectiva, é para a organização o que a personalidade é para o indivíduo. E a forma de ver, interpretar e agir sobre o mundo, regulando o comportamento por meio de um conjunto de normas e valores compartilhados pela organização.

Estas cinco dimensões de estratégia não são mutuamente excludentes. Ao contrário, se integram, inter-relacionam e complementam. Tais dimensões não são somente uma base sistematizada que gera uma noção de como lidar com os concorrentes, mas constituem, também, um provocativo capaz de potencializar o processo de exercício estratégico, ou seja, a reflexão, a antecipação do futuro pretendido (planejamento) e a ação coletiva dentro da empresa, focada em resultados, como, por exemplo, volume de negócios (receitas), participação de mercado, lucratividade e rentabilidade (MINTZBERG,
1987; MINTZBERG; AHLSTRAND; LAMPEL, 2000; MINTZBERG, 2004; MINTZBERG et al., 2006).

\section{A imagem e sua influência no comportamento dos estrategistas}

Os esquemas interpretativos, ou imagens, possuem um papel fundamental no direcionamento estratégico das organizações. Por meio das imagens é possível moldar o pensamento e direcionar as ações estratégicas das organizações (MACHADODA-SILVA; FONSECA; FERNANDES, 2000).

Para Chapman e Ferfolja (2001), os modelos mentais não são simplesmente repositórios de aprendizado passado, mas também as bases para a interpretação do que esteja acontecendo atualmente. Eles influenciam fortemente a ação das pessoas através do viés cognitivo. Este viés tem como efeito a focalização e o enrijecimento da reflexão estratégica. Dessa forma, tem-se a tendência de tomar decisões baseadas em pressupostos conhecidos, em princípios que evitam um contato direto com o desconhecido. Cada viés é construído pela história do indivíduo e/ou da organização. Histórias de sucesso ou de fracasso são grandes formadores de vieses para o direcionamento de futuras decisões, baseadas em pressupostos anteriores (MACHADO-DA-SILVA; FONSECA; FERNANDES, 2000; GENTNER, 1983).

Cabe salientar que as imagens constituem os conceitos e as relações que um indivíduo utiliza para compreender as várias situações ou os ambientes em que está inserido. As imagens fornecem um ponto de referência, representando uma âncora, um começo a partir do qual se inicia a ação. As imagens atuais determinam quais informações receberão mais atenção ou não, e expressam o modo como as pessoas vêem ou representam um objeto.

Assim, imagens fortemente arraigadas podem levar os gestores à não enxergar mudanças ambientais (internas e externas) relevantes e a não tomar decisões adequadas, rapidamente. Fica evidente, então, que as imagens refletem o que se conhece e como se conhece, ou seja, influenciam como o sujeito assiste e como ele processa as informações que recebe sobre o contexto 
(RODRÍGUEZ, 1996; ZALTMAN, 1997; SENGE, 1998; MACHADO-DA-SILVA; FONSECA; FERNANDES, 2000), impactando, em última análise, em sua atitude, em sua ação.

\section{MÉTODO DE PESQUISA}

\section{A técnica de configuração de imagens ideativas (TCID) e os objetivos da pesquisa}

A partir da questão central de pesquisa: qual imagem de estratégia organizacional emerge da ótica dos profissionais ligados à gestão empresarial, na região da Serra Gaúcha?, É proposta a utilização de uma técnica derivada do Método de Configuração de Imagem (MCI), como um instrumento adequado para essa finalidade.

$\mathrm{O}$ instrumento de pesquisa adotado no trabalho se baseia em métodos já desenvolvidos e validados, tais como Customer Window (APDG, 1994) e Framework for Marketing Image Management (BARICH; KOTLER, 1991), assim como métodos desenvolvidos por pesquisadores europeus para acessar a configuração das representações sociais (ABRIC, 1984; MINAYO, 1997; MOSCOVICI, 1978, 2000; SÁ, 1996). O desenvolvimento do MCI é resultado de muitos anos de pesquisa acadêmica, desde 1998 (CAIERON JÚNIOR, 1999; CHALA, 2000; DE TONI, 1998, 2005; DE TONI; MILAN; BARAZETTI, 2004; DE TONI; MILAN; SCHULER, 2005; DE TONI; SCHULER, 2002; DE TONI; SCHULER, 2004; KRAFT; NIQUE, 2002; SAMPAIO, 1998; SCHULER, 2000, 2004).

Nesse trabalho é explorada a possibilidade de criação de mais uma técnica específica, derivada desse método, agora direcionada à configuração de Imagens Ideativas, ou seja, idéias, conceitos e abstrações. Sendo assim, com uma abordagem predominantemente exploratória, o trabalho apresenta os seguintes objetivos específicos: (i) identificar os atributos salientes da imagem de estratégia organizacional na ótica dos entrevistados (gestores de empresas da Serra Gaúcha); (ii) identificar a Imagem Central e a Imagem Periférica do conceito em estudo (estratégia organizacional); (iii) classificar os atributos identificados dentre as cinco dimensões propostas por Mintzberg (1987), os 5 Ps e (iv) apresentar uma disposição gráfica dos resultados por meio do Gráfico de Configuração da Imagem (GCI), permitindo a visualização da configuração da imagem de estratégia organizacional, para essa amostra.

\section{Amostra}

A amostra é não-probabilística, estabelecida por conveniência (MALHOTRA, 2001). Foram abordados profissionais ligados à gestão de empresas, que estão intimamente relacionados a definição e implementação de estratégias organizacionais. Tais profissionais estão ligados a 46 empresas diferentes, localizadas em uma cidade do interior do Estado do Rio Grande do Sul (RS), mais especificamente, na região da Serra Gaúcha.

Foram contempladas, na pesquisa, tanto empresas do setor da indústria (29 empresas), quanto do setor de comércio e serviços (17 empresas). Dos entrevistados, 16 são empresários (proprietários das empresas) e 30 executivos (Tabela 1).

TABELA 1 - Descrição da amostra

\begin{tabular}{c|cc|cc|cccc}
\hline Resultados & \multicolumn{2}{|c|}{ Setor } & \multicolumn{2}{c|}{ Função } & Idade & Sexo \\
\hline & Indústria & $\begin{array}{c}\text { Comércio } \\
\text { e Serviços }\end{array}$ & $\begin{array}{c}\text { Empresário } \\
\text { (Proprietário) }\end{array}$ & Executivo & $\begin{array}{c}<30 \\
\text { anos }\end{array}$ & $\begin{array}{c}> \\
\text { anos }\end{array}$ & M & F \\
\hline $\begin{array}{c}\text { Freqüência } \\
\%\end{array}$ & 29 & 17 & 16 & 30 & 14 & 31,1 & 34 & 11 \\
73 & 37 & 34,8 & 65,2 & 31,1 & 58,9 & 75,6 & 24,4 \\
\hline
\end{tabular}

Fonte: Dados provenientes da pesquisa. 


\section{O instrumento de coleta de dados e a condução das entrevistas}

A configuração do conteúdo das imagens pode ser feita por meio de entrevistas individuais, argüindo-se os entrevistados sobre suas percepções e convicções. No entanto, somente perguntas diretas, em torno do assunto pesquisado, não são suficientes, pois as pessoas geralmente não articulam plenamente seus conhecimentos, opiniões e idéias quando abordadas dessa maneira (GENTNER, 2001).

Ao considerar a natureza global ou holística da imagem, modelos de mensuração com apenas escalas fechadas, tais como hierarquias, lista de apelos e ordens de importância, necessitam ser complementados com outras abordagens, pois tais técnicas apenas captam fatos específicos e não representações, impressões e redes de significados (DICHTER, 1985).

Com o intuito de substituir as perguntas diretas simples por um conjunto de estímulos capaz de revelar um pouco mais do conteúdo das imagens mentais dos respondentes, foi utilizado um roteiro básico de questões com o intuito de estimular a evocação espontânea de atributos pertencentes às várias categorias de elementos que, teoricamente, compõem as imagens na perspectiva dos entrevistados, conforme mostra o Quadro 1.

QUADRO 1 - Roteiro básico de questões

\begin{tabular}{ll}
\hline Roteiro Básico de Questões & Tipo de Evocação \\
\hline 1. Quando eu digo Estratégia Organizacional qual a primeira coisa que lhe vem à mente? & Top of Mind \\
2. Que outras idéias lhe vêm à mente sobre Estratégia Organizacional? & Geral \\
3. Como você descreve a Estratégia Organizacional? & Cognitiva \\
4. Qual o significado de Estratégia Organizacional na sua empresa? & Simbólica \\
5. Quais os sentimentos que lhe vêm à mente quando eu digo Estratégia Organizacional? & Emocional \\
6. Quais os benefícios que a Estratégia Organizacional traz para a sua empresa? & Funcional \\
\hline
\end{tabular}

Fonte: Elaborado pelos autores, mediante revisão da literatura.

Em relação às questões utilizadas, alguns comentários são pertinentes. As questões 1 e 2 auxiliam na identificação dos atributos mais prontamente evocados, que emergem da memória do entrevistado, quando o objeto de pesquisa é citado, no caso, o conceito de estratégia organizacional. Essas duas questões buscam verificar o tom geral da representação mental que o entrevistado tem sobre o conceito.

Segundo Poiesz (1989), quando são criadas condições de descontração para o entrevistado, assegurando-lhe que não existe resposta certa ou errada e que nada específico é esperado dele, além de uma relação leve e lúdica com a situação de pesquisa, a latência nas respostas do tipo "a primeira coisa que lhe vem à cabeça" é útil para avaliar os conceitos sem que o entrevistado possa refletir muito sobre a dimensão que está sendo julgada, garantindo, assim, um pouco mais de espontaneidade às suas respostas. Para essas duas questões iniciais, portanto, empregou-se a livre associação de idéias, que é uma das formas mais utilizadas para identificar as imagens que as pessoas formam sobre objetos ou conceitos (GUIMELLI, 1994).

Quanto às questões 3 a 6 , as mesmas buscam dar uma maior consistência à coleta de dados ao repetir o mesmo questionamento básico através de outras perspectivas (abordagens cognitiva, emocional e funcional), formando, assim, uma escala unidimensional que se interessa em propor ao entrevistado um maior número de oportunidades de revelar os conceitos que fazem parte da configuração da sua imagem.

Com base no roteiro básico de questões (Quadro 1), as entrevistas foram conduzidas de forma individual e em sessão única. A duração média das entrevistas foi de 30 minutos.

\section{Tratamento dos dados}

O tratamento dos dados foi realizado em três etapas. A primeira etapa consistiu da análise de conteúdo das respostas obtidas, observando os 
pressupostos apregoados por Bardin (2004). A partir da análise de conteúdo, foram listados todos os atributos mencionados pelos entrevistados. Dessa forma, foi gerado o conjunto de atributos que formam a imagem de estratégia organizacional para a amostra em análise.

$\mathrm{Na}$ segunda etapa, foram levantadas a freqüência e a ordem de evocação dos atributos, conforme proposto por Abric (1984) e Vergès (1992), visando criar uma distinção entre os atributos mais próximos e os mais distantes, em relação ao termo indutor empregado (estratégia organizacional). Os atributos mais próximos são considerados pertencentes à Imagem Central, enquanto os mais distantes à Periferia da Imagem.

Para cada um dos atributos identificados foram calculados o Valor de Freqüência (VF) e o Valor de Ordem (VO). Para calcular o VO, adotou-se o seguinte procedimento: quando o atributo foi citado em primeiro lugar, o mesmo recebeu um valor 5; em segundo lugar, valor 4; em terceiro lugar, valor 3 ; em quarto lugar, valor 2 e, em quinto lugar, valor 1 . A partir do sexta posição de evocação os atributos não receberam mais valor algum. Finalmente, foi calculado o Valor Total (VT) para cada atributo, o qual representa um somatório simples entre VF e VO.

Para a atribuição das zonas de proximidade com o termo indutor, foi utilizado como critério discriminatório o VT dos atributos. A partir do VT, foi aplicado o procedimento de "Divisão em Quartis". Por meio desta divisão, foram criados quatro intervalos. O intervalo gerado pelo quarto quartil, que corresponde aos valores mais altos, acolheu os atributos considerados como pertinentes à Imagem Central. O terceiro quartil corresponde ao intervalo do segundo valor mais alto, configurando-se como a Primeira Periferia da Imagem. O segundo quartil corresponde ao intervalo de terceiro valor mais alto e foi denominado Segunda Periferia. $\mathrm{E}$, finalmente, o primeiro quartil, que correspondente ao intervalo de valores menores, denominado Periferia da Imagem.
A terceira etapa contemplou a categorização dos atributos da imagem de estratégia organizacional a partir das dimensões propostas por Mintzberg (1987), os 5 Ps. Nesta etapa também foi utilizada a análise de conteúdo por parte dos pesquisadores, sendo que, para a ponderação dos atributos foi adotado o critério do VT.

Os resultados identificados nestas etapas da pesquisa foram dispostos graficamente no Gráfico de Configuração das Imagens (GCI), que apresenta três informações essenciais: os atributos que compõem as imagens, a proximidade destes com a Imagem Central e a dimensão ou categoria a que pertencem (um dos 5 Ps de Mintzberg).

\section{ANÁLISE DOS RESULTADOS}

\section{Identificação dos atributos e sua proximidade com o termo indutor}

Pela análise de conteúdo das respostas provenientes das entrevistas individuais, foram identificados vinte e oito atributos. Estes atributos salientes formam a imagem de estratégia organizacional na ótica dos entrevistados.

A partir dos atributos identificados e do cálculo de VF, VO e VT, procedeu-se a aferição dos Quartis (Tabela 2), possibilitando a apresentação da divisão, por áreas, de proximidade com o termo indutor, ou seja, a identificação da Imagem Central, Primeira Periferia, Segunda Periferia e Periferia de acordo com o Quadro 2.

TABELA 2 - Áreas de proximidade dos atributos em relação ao termo indutor

\begin{tabular}{ccc}
\hline Quartis & $\begin{array}{c}\text { Proximidade com o } \\
\text { Termo Indutor }\end{array}$ & $\begin{array}{c}\text { Intervalo } \\
\text { do VT }\end{array}$ \\
\hline 4 & Imagem Central & VT de 216 a 40,5 \\
3 & $1^{\text {a } \text { Periferia }}$ & $<40,5$ a 23,5 \\
2 & $2^{\text {a } \text { Periferia }}$ & $<23,5$ a 14 \\
1 & Periferia & $<14$ a 2 \\
\hline
\end{tabular}

Fonte: Dados provenientes da pesquisa. 
QUADRO 2 - Atributos identificados e sua proximidade com o termo indutor

\begin{tabular}{llllll}
\hline Imagens & N. & Atributos Identificados & VF & VO & VT \\
\hline & 1 & Sistematização: organização das atividades & 58 & 158 & 216 \\
& 2 & Planejamento: pensar o futuro & 62 & 129 & 191 \\
& 3 & Objetivos e metas a serem atingidas & 48 & 88 & 136 \\
Imagem & 4 & Direção: curso de ação, caminho ou direcionamento & 29 & 53 & 82 \\
Central & 5 & Resultados: faturamento, participação de mercado, lucro e rentabilidade & 35 & 26 & 61 \\
& 6 & Orientação para mercado & 28 & 17 & 45 \\
& 7 & Posição competitiva em relação à concorrência & 19 & 26 & 45 \\
& 8 & Envolvimento: comprometimento de todos & 24 & 15 & 39 \\
& 9 & Implementação: ação, atitude, pôr em prática & 16 & 23 & 39 \\
Primeira & 10 & Desenvolvimento: crescimento e evolução do negócio & 19 & 15 & 34 \\
Periferia & 11 & Melhoria interna: redução de custos, produtividade, etc. & 15 & 18 & 33 \\
& 12 & Direcionamento ou alocação adequada de recursos & 13 & 18 & 31 \\
& 13 & Perspectiva: modelos, estruturação, normas e valores & 9 & 18 & 27 \\
& 14 & Satisfação, realização & 20 & 4 & 24 \\
& 15 & Manobra para enfrentar os concorrentes & 11 & 12 & 23 \\
& 16 & Responsabilidade & 9 & 8 & 17 \\
Segunda & 17 & Segurança & 12 & 5 & 17 \\
Periferia & 18 & Tomada de decisão & 5 & 12 & 17 \\
& 19 & Vantagem competitiva & 6 & 9 & 15 \\
& 20 & Competitividade & 8 & 6 & 14 \\
& 21 & Conhecimento & 9 & 5 & 14 \\
& 22 & Diagnóstico organizacional: verificação dos pontos fortes e fracos, & 9 & 5 & 14 \\
& & oportunidades e ameaças, busca de informações & & & \\
& 23 & Melhoria de resultados & 7 & 5 & 12 \\
Periferia & 24 & Ferramenta de trabalho & 6 & 5 & 11 \\
& 25 & Algo necessário & 4 & 7 & 11 \\
& 26 & Controle & 5 & 1 & 6 \\
& 27 & Diferenciação & 2 & 3 & 5 \\
& 28 & Relacionamento: credibilidade e confiança & 2 & 0 & 2 \\
\hline
\end{tabular}

Fonte: Dados provenientes da pesquisa.

\section{Classificação dos atributos a partir das dimensões de estratégia (5 Ps)}

Os atributos identificados foram classificados, mediante análise de conteúdo e julgamento dos pesquisadores, dentre as cinco dimensões de estratégia organizacional propostas por Mintzberg (1987), também denominadas 5 Ps: Plano, Pretexto, Padrão, Posição e Perspectiva.
O resultado dessa classificação é apresentado no Quadro 3. Nas duas colunas da direita encontram-se os VTs associados a cada atributo, assim como o percentual que ele representa na soma de todos os VTs encontrados. Além disso, encontram-se também, o VT associado a cada categoria de atributos, segundo a classificação de Mintzberg, bem como o percentual do V'T geral dos atributos que cada categoria representa. 
QUADRO 3 - Agrupamento dos atributos em suas respectivas dimensões

\begin{tabular}{|c|c|c|c|}
\hline Dimensões - 5 Ps & Atributos de Cada uma das Dimensões & V'T & $\%$ \\
\hline \multirow[t]{5}{*}{ Plano } & Direcionamento ou alocação adequada de recursos & 31 & 2,62 \\
\hline & Direção: curso de ação, caminho ou direcionamento & 82 & 6,94 \\
\hline & Objetivos e metas a serem atingidas & 136 & 11,52 \\
\hline & Planejamento: pensar o futuro & 191 & 16,17 \\
\hline & Subtotal & 440 & 37,26 \\
\hline \multirow[t]{5}{*}{ Pretexto } & Diferenciação & 5 & 0,42 \\
\hline & Competitividade & 14 & 1,19 \\
\hline & Manobra para enfrentar os concorrentes & 23 & 1,95 \\
\hline & Vantagem competitiva & 15 & 1,27 \\
\hline & Subtotal & 57 & 4,83 \\
\hline \multirow[t]{7}{*}{ Padrão } & $\begin{array}{l}\text { Resultados: faturamento, participação de mercado, lucro e } \\
\text { rentabilidade }\end{array}$ & 61 & 5,17 \\
\hline & Melhoria de resultados & 12 & 1,02 \\
\hline & Melhoria interna: redução de custos, produtividade, etc. & 33 & 2,79 \\
\hline & Implementação: ação, atitude, pôr em prática & 39 & 3,30 \\
\hline & Ferramenta de trabalho & 11 & 0,93 \\
\hline & Desenvolvimento: crescimento e evolução do negócio & 34 & 2,88 \\
\hline & Subtotal & 190 & 16,09 \\
\hline \multirow[t]{6}{*}{ Posição } & Posição competitiva em relação à concorrência & 45 & 3,81 \\
\hline & Orientação para o mercado & 45 & 3,81 \\
\hline & Responsabilidade & 17 & 1,44 \\
\hline & Relacionamento: credibilidade e confiança & 2 & 0,17 \\
\hline & Tomada de decisão & 17 & 1,44 \\
\hline & Subtotal & 126 & 10,67 \\
\hline \multirow[t]{11}{*}{ Perspectiva } & Perspectiva: modelos, estruturação, normas e valores & 27 & 2,29 \\
\hline & $\begin{array}{l}\text { Diagnóstico organizacional: verificação dos pontos fortes } \\
\text { e fracos, oportunidades e ameaças, busca de informação }\end{array}$ & 14 & 1,19 \\
\hline & Sistematização: organização das atividades & 216 & 18,29 \\
\hline & Satisfação, realização & 24 & 2,03 \\
\hline & Envolvimento: comprometimento de todos & 39 & 3,30 \\
\hline & Segurança & 17 & 1,44 \\
\hline & Algo necessário & 11 & 0,93 \\
\hline & Controle & 6 & 0,51 \\
\hline & Conhecimento & 14 & 1,19 \\
\hline & Subtotal & 368 & 31,16 \\
\hline & Soma dos Valores Totais & 1.181 & 100,00 \\
\hline
\end{tabular}

Fonte: Dados provenientes da pesquisa.

Observa-se que as dimensões Plano $(37,26 \%)$ e Perspectiva $(31,16 \%)$ concentram os maiores percentuais do VT geral dos atributos, o que quer dizer que os atributos classificados nessas categorias são os mais freqüentemente e prontamente citados pelos entrevistados. Segundo a Teoria do Núcleo Central, pode-se pensar que esses atributos sejam mais representativos do entendimento comum dos profissionais entrevistados sobre estratégia organizacional. Note-se que os dois atributos pertencentes ao Núcleo Central da Imagem para esses respondentes encontram-se, cada 
um, numa dessas duas dimensões, sugerindo consistência nos resultados dos dois tratamentos.

As demais dimensões, Padrão (16,09\%), Posição (10,67\%) e Pretexto (4,83\%) apresentam, seqüencialmente, valores menores indicando que foram citados de forma menos freqüente e pronta. Comportam os atributos dispostos na Periferia da imagem de estratégia, com exceção do atributo Resultados, que se encontra na Segunda Periferia.

Em relação a composição de cada uma das dimensões (Quadro 3), é possível relacionar os principais atributos inerentes a cada uma delas. Para a dimensão Plano, os principais atributos são: "planejamento: pensar o futuro" (16,17\%) e "objetivos e metas a serem atingidas" (11,52\%). Para a dimensão Pretexto, "manobra para enfrentar os concorrentes" (1,95\%), "vantagem competitiva" $(1,27 \%)$ e "competitividade" (1,19\%). Para a dimensão Padrão, "resultados: faturamento, participação de mercado, lucro e rentabilidade" (5,17\%) e "implementação: ação, atitude, pôr em prática" (3,30\%). Para a dimensão Posição, "posição competitiva em relação à concorrência" e "orientação para mercado" (3,81\% para ambos os atributos). E, por fim, a dimensão Perspectiva, "sistematização: organização das atividades" $(18,29 \%)$ e "envolvimento: comprometimento de todos" $(3,30 \%)$.

\section{Gráfico de configuração da imagem (GCI)}

O Gráfico da Configuração da Imagem (GCI), apresentado na Figura 1, ilustra, em uma representação gráfica, as principais informações sobre a imagem de estratégia organizacional, para esse conjunto de respondentes, que a aplicação do MCI gerou.

O GCI disponibiliza três informações úteis para a visualização de imagem de estratégia organizacional: (i) os atributos que compõem a imagem de estratégia organizacional; (ii) as categorias de atributos, a partir dos 5 Ps de estratégia, propostos por Mintzberg (1987) e (iii) a proximidade dos atributos com o termo indutor empregado (estratégia organizacional).

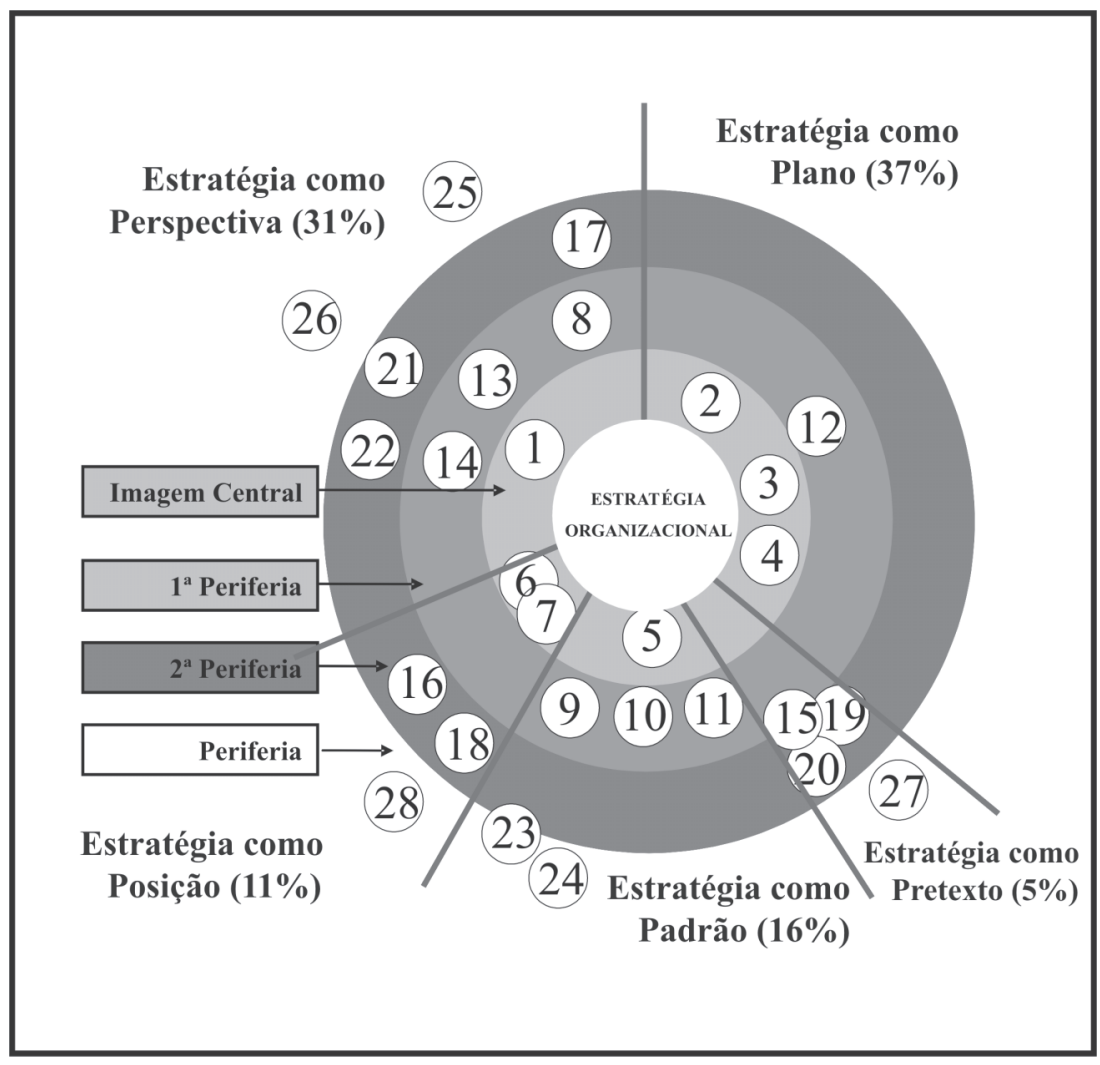

\begin{tabular}{|c|c|c|c|}
\hline $\mathbf{N}^{\mathbf{0}}$ & Atributos & $\mathbf{N}^{\mathbf{0}}$ & Atributos \\
\hline 1 & Sistematização & 15 & $\begin{array}{l}\text { Manobra para } \\
\text { enfrentar os } \\
\text { concorrentes }\end{array}$ \\
\hline 2 & Planejamento & 16 & $\begin{array}{l}\text { Responsabilida } \\
\text { de }\end{array}$ \\
\hline 3 & $\begin{array}{l}\text { Objetivos e } \\
\text { metas }\end{array}$ & 17 & Segurança \\
\hline 4 & Direção & 18 & $\begin{array}{l}\text { Tomada de } \\
\text { decisão }\end{array}$ \\
\hline 5 & Resultados & 19 & $\begin{array}{l}\text { Vantagem } \\
\text { competitiva }\end{array}$ \\
\hline 6 & $\begin{array}{l}\text { Orientação para } \\
\text { mercado }\end{array}$ & 20 & $\begin{array}{l}\text { Competitivi- } \\
\text { dade }\end{array}$ \\
\hline 7 & $\begin{array}{l}\text { Posição } \\
\text { competitiva }\end{array}$ & 21 & Conhecimento \\
\hline 8 & $\begin{array}{l}\text { Envolvimento } \\
\text { de todos }\end{array}$ & 22 & $\begin{array}{l}\text { Diagnóstico } \\
\text { organizacional }\end{array}$ \\
\hline 9 & Implementação & 23 & $\begin{array}{l}\text { Melhoria de } \\
\text { resultados }\end{array}$ \\
\hline 10 & $\begin{array}{l}\text { Desenvolvi- } \\
\text { mento }\end{array}$ & 24 & $\begin{array}{l}\text { Ferramenta de } \\
\text { trabalho }\end{array}$ \\
\hline 11 & $\begin{array}{l}\text { Melhoria } \\
\text { interna }\end{array}$ & 25 & $\begin{array}{l}\text { Algo } \\
\text { necessário }\end{array}$ \\
\hline 12 & $\begin{array}{l}\text { Alocação } \\
\text { adequada de } \\
\text { recursos }\end{array}$ & 26 & Controle \\
\hline 13 & Perspectiva & 27 & Diferenciação \\
\hline 14 & $\begin{array}{l}\text { Satisfação, } \\
\text { realização }\end{array}$ & 28 & $\begin{array}{l}\text { Relacionamen- } \\
\text { to }\end{array}$ \\
\hline
\end{tabular}

FIGURA 1 - Gráfico da Configuração da Imagem do conceito de estratégia organizacional

Fonte: Dados provenientes da pesquisa. 
O GCI de Estratégia Organizacional, para a amostra pesquisada, configura uma idéia cuja Imagem Central é constituída dos atributos (sistematização - organização das atividades -e planejamento - pensar no futuro; objetivos e metas a serem atingidas; direção - curso de ação, caminho; resultados - faturamento, lucro e resultado; orientação para mercado e posição competitiva). Esses atributos são responsáveis pela sustentação daimagem compartilhada por esse grupo de gestores.

Todos os demais atributos da imagem são fugazes, encontrando-se principalmente na última periferia, o que indica que não são amplamente compartilhados, nem prontamente lembrados. Pode haver um reflexo, aqui, da forte relação nas mentes desses executivos entre estratégia e planejamento formal. A estratégia como padrão, de natureza eminentemente emergente (não deliberada) e fortemente depentende da aprendizagem organizacional (MINTZBERG; AHLSTRAND; LAMPEL, 2000), parece mais difícil de ser percebida, mesmo que existam exemplos de empresas, altamente flexíveis, que conseguiram desempenhos excelentes em ações que não foram formalmente planejadas e que as transformaram em modelos.

Por outro lado, a adaptação de estratégias planejadas é muitas vezes desencorajada pela articulação de intenções e pela separação entre formulação e implementação de estratégias - várias organizações planejam não para se tornarem flexíveis, mas somente para realizarem intenções específicas e não se dão conta que, além da necessidade da direção para que as intenções se realizem, é importante responder a padrões de ação emergentes (MINTZBERG; WATERS, 1985).

Em relação as dimensões de Mintzberg, a que mais se sustenta na imagem, apesar de composta por poucos atributos, é a visão de estratégia organizacional como Plano (pensar no futuro; objetivos e metas a serem atingidos; direção: curso de ação, caminho ou direcionamento; alocação adequada de recursos). Essa dimensão comporta um conjunto de atributos mais próximos do Núcleo Central, perfazendo 37\% do Valor Total encontrado no conjunto geral de atributos dessa imagem. Para um gestor que deseje prever tendências $\mathrm{da}$ competição nesse ambiente de negócios seria possível supor que as organizações estarão direcionando seus planejamentos estratégicos principalmente com foco nessas questões.
A dimensão mais fracamente abordada pela amostra é a visão da estratégia como Pretexto, que comporta quatro atributos da última periferia (manobra para enfrentar concorrentes, vantagem competitiva, competitividade; diferenciação), perfazendo 5\% do Valor Total encontrado no conjunto geral de atributos dessa imagem. Esse resultado indicaria, aos professores e consultores da região, as áreas a serem abordadas para melhor preparar os gestores para enfrentar as dificuldades de desenvolvimento de seus negócios. Tal resultado sugere também, oportunidades de foco para quem deseja vencer nesse ambiente, uma vez que essas idéias são mais dificilmente acessadas pelos gestores da região.

Teoricamente, a diferenciação em relação aos concorrentes, através de um atendimento melhor das necessidades, desejos e expectativas dos clientes, de um produto e/ou um serviço inovador ou com qualidade superior, gera um valor superior para o cliente e aumenta a possibilidade de desempenho da empresa (SONG; PARRY, 1997; COOPER, 2000; HENARD; SZYMANSKI, 2001).

Da mesma forma, o conceito de relacionamento, que obteve o menor Valor Total do conjunto de atributos, remete para a necessidade de uma mudança de filosofia empresarial, para um novo modo de pensar as relações organizacionais, criando valor para o cliente e, por conseguinte, fazendo com que o nível de competitividade da empresa aumente. A habilidade da empresa em proporcionar um valor superior ao cliente, e seus stakeholders, é considerada uma das capacidades empresariais mais direcionadas ao sucesso do negócio. Nesta perspectiva, comprador e vendedor podem ser vistos como parceiros de troca na busca de ganhos mútuos por meio da cooperação, da confiança, da orientação de longo prazo e do compromisso entre as partes (HUNT; MORGAN, 1994; GRÖNROOS, 2000; BERRY, 2002).

\section{CONSIDERAÇÕES FINAIS}

Apesar da natureza exploratória deste estudo, pode-se observar que os resultados são bastante interessantes, no que se refere a identificação da imagem de estratégia organizacional para alguns gestores de empresas dessa região. 
Esses resultados sugerem que a Técnica de Configuração de Imagens Ideativas (TCID) pode ser adequada para a finalidade que pretende, convidando a testes mais profundos de validade $\mathrm{e}$ confiabilidade.

O aporte teórico de Mintzberg (1987) sobre os 5 Ps de estratégia, que direcionou a categorização do conceito em dimensões, contribuiu muito para formatar as imagens dos gestores entrevistados. No caso da mensuração de outras idéias, na falta de categorias assumidas a priori, com base na literatura, pode-se utilizar a análise fatorial exploratória para verificar a formação espontânea de categorias ou dimensões dentro do conjunto de atributos salientes levantados na amostra.

O MCI anteriormente foi utilizado para gerar técnicas de configuração de imagens de organizações, produtos, serviços e marcas. Aqui houve um esforço de pesquisa para gerar uma técnica de configuração de imagens de objetos puramente ideativos, tal como conceitos. Assim, a identificação das imagens de conceitos, tais como a de estratégia organizacional, constitui uma oportunidade relevante para melhor compreender determinados comportamentos no ambiente empresarial, possibilitando a implementação de ações para manter ou modificar a imagem existente e seus respectivos efeitos e resultados.

Desta forma, é possível refletir sobre os modelos ou esquemas vigentes nas mentes dos executivos e de como isso pode direcionar a forma como eles enxergam seus mundos, se relacionam com seus ambientes e tomam decisões, uma vez que "são os significados atribuídos pelos indivíduos à realidade em que se acham inseridos que conformam seu contexto institucional de referência, ou seja, que definem estruturas e orientam ações organizacionais" (CARVALHO; VIEIRA; GOULART, 2005, p. 865).

Neste sentido, como afirma Morgan (2000), é preciso, para um gestor que ajuda as empresas a se adaptar a inúmeras exigências de um mundo cada vez mais turbulento, ter consciência das imagens e pressupostos que determinam seu atual modo de pensar e desenvolver a capacidade de usar novas imagens e pressupostos.

\section{REFERÊNCIAS}

ABRIC, J. C. A theoretical and experimental approach to the study of social representations in a situation of interaction. In: FARR, R. M.; MOSCOVICI, S. (Ed.). Social representations. Cambridge: Cambridge University Press, 1984. p. 169-183.

Central system, peripheral system: their functions and roles in the dynamics of social representations. Papers on Social Representations, v. 2, p. 75-78, 1993. Disponível em: $<$ http://www.psr.jku.at/psrindex.htm>. Acesso em: 10 set. 2003.

ASSESSORIA DE PESQUISA E DESENVOLVIMENTO GERENCIAL - APDG. Customer window: catálogo de informações. São Paulo: Rhodia, 1994.

BARDIN, L. Análise de conteúdo. 3. ed. Lisboa: Edições 70, 2004.

BARICH, H.; KOTLER, P. A framework for marketing image management. Sloan Management Review, v. 32, n. 2, p. 97-104, 1991.

BERRY, L. L. Relationship marketing of services - perspectivs from 1983 and 2000. Journal of Relationship Marketing, v. 1, n. 1, p. 59-77, 2002.

BREAKWELL, G. M. Mental models and social representations of hazards: the significance of identity processes. Journal of Risk Research, v. 4, n. 4, p. 341-351, 2001.

CAIERON JÚNIOR, A. A identificação da imagem institucional do ponto de vista do funcionário. 1999. 39 f. Monografia (Trabalho de Conclusão do Curso de Administração) - Escola de Administração, Universidade Federal do Rio Grande do Sul, Porto Alegre, 1999.

CARVAlHO, C. A.; VIEIRA, M. M. F.; GOULART, S. A trajetória conservadora da teoria institucional. Revista de Administração Pública, v. 39, n. 4, p. 849-874, 2005. 
CHALA, A. A universidade pública como representação social: levantamento do Núcleo Central da Representação da UFRGS entre seus estudantes de graduação. 2000. $146 \mathrm{f}$. Dissertação (Mestrado em Comunicação) Faculdade de Biblioteconomia e Comunicação, Universidade Federal do Rio Grande do Sul, Porto Alegre, 2000.

CHAPMAN, J. A.; FERFOLJA, T. Fatal flaws: the acquisition of imperfect mental models and their use in hazardous situations. Journal of Intellectual Capital, v. 2, n. 4, p. 398-409, 2001.

COOPER, R. G. Winning with new products: do it right. Ivey Business Journal, v. 64, n. 6, p. 54-60, 2000.

DE TONI, D. O processo de desenvolvimento de novos produtos: um estudo de caso a indústria plástica do segmento de acessórios para móveis. 1988. 150 f. Dissertação (Mestrado em Administração) - Escola de Administração, Universidade Federal do Rio Grande do Sul, Porto Alegre, 1998.

Administração da imagem de produtos: desenvolvendo um instrumento para a configuração da imagem de produto. 2005. 268 f. Tese (Doutorado em Administração) - Escola de Administração, Universidade Federal do Rio Grande do Sul, Porto Alegre, 2005.

DE TONI, D.; MILAN, G. S.; SCHULER, M. Configuração de imagens de serviços: um estudo aplicado aos serviços de fisioterapia disponibilizados por um plano de saúde. In: ENCONTRO ANUAL DA ASSOCIAÇÃO NACIONAL DE PÓS-GRADUAÇÃO E PESQUISA EM ADMINISTRAÇÃO, 29., 2005, Brasília. Anais... Brasília: EnANPAD, 2005. p. 1-16.

DE TONI, D.; MILAN, G. S.; BARAZETTI, L. Imagens de serviços: um estudo exploratório sobre a configuração e organização das imagens dos serviços de fisioterapia de um plano de saúde. In: ENCONTRO ANUAL DA ASSOCIAÇÃO NACIONAL DE PÓS-GRADUACÃO E PESQUISA EM ADMINISTRAÇĂ̊O, 28., 2004, Curitiba. Anais... Curitiba: EnANPAD, 2004. p. 1-16.
DE TONI, D.; SCHULER, M. Gestão de imagens de produtos: uma mensuração das imagens do vinho. In: ASSEMBLÉIA DO CLADEA, 37., 2002, Porto Alegre. Anais... Porto Alegre: CLADEA, 2002. p. 1-16.

DE TONI, D.; SCHULER, M. Gestão de imagem: desenvolvendo um instrumento para a configuração da imagem de produto. In: ENCONTRO ANUAL DA ASSOCIAÇÃO NACIONAL DE PÓS-GRADUAÇÃO E PESQUISA EM ADMINISTRAÇÃO, 28., 2004, Curitiba. Anais... Curitiba: EnANPAD, 2004. p. 1-16.

DICHTER, E. What's in an image. Journal of Consumer Marketing, v. 2, n. 1, p. 75-81, 1985.

EISENHARDT, K. M. Strategy as strategic decision making. Sloan Management Review, v. 40, n. 3, p. 65-72, 1999.

FONSECA, V. S.; MACHADO-DA-SILVA, C. L. Indivíduo, organização e ambiente: bases para a conversação entre três perspectivas de estudo da estratégia em organizações. In: ENCONTRO ANUAL DA ASSOCIAÇÃO NACIONAL DE PÓS-GRADUAÇÃO E PESQUISA EM ADMINISTRAÇÃO, 25., 2001, Campinas. Anais... Campinas: EnANPAD, 2001. p. 1-16.

GENTNER D. Folowing waters or teeming crowds: mental models of electricity. In: GENTNER D.; STEVENS A. L. (Ed.). Mental models. Hillsdale: Erlbaum, 1983. p. 99-129.

Psychology of mental model. In: SMELSE, N.; BATES, P. (Ed.). International encyclopedia of the social and behavioral science. London: Elsevier, 2001. p. 9683-9687.

GRÖNROOS, C. Relationship marketing: the nordic school perspective. In: SHETH, J. N.; PARVATIYAR, A. (Ed.). Handbook of relationship marketing. Thousand Oaks: Sage Publications, 2000. Chapter 4, p. 95-117.

GUIMELLI, C. Transformation des représentations sociales, pratiques nouvelles et schèmes cognitifs de base. In: GUIMELLI, C. (Ed.). Structures et transformations des représentations sociales. Lausanne: Delachaux et Niestlé, 1994. p. 171-198. 
HENARD, D. H.; SZYMANSKI, D. M. Why some new products are more successful than others. Journal of Marketing Research, v. 38, n. 3, p. 362-375, 2001.

HOOLEY, G. J.; SAUNDERS, J. A.; PIERCY, N. F. Estratégia de marketing e posicionamento competitivo. 3. ed. São Paulo: Prentice Hall, 2005.

HUNT, S. D.; MORGAN, R. M. Relationship marketing in the era of network competition. Marketing Management, v. 3, n. 1, p. 19-28, 1994.

JAIN, S. C. Marketing planning and strategy. $6^{\text {th }}$ ed. Cincinnati: South-Western College, 2000.

KRAFT, S. E. R. H.; NIQUE, W. M. Desvendando o consumidor através das metáforas: uma aplicação da Zaltman Metaphor Elicitation Technique (ZMET). In: ENCONTRO ANUAL DA ASSOCIAÇÃO NACIONAL DE PÓS-GRADUAÇÃO E PESQUISA EM ADMINISTRAÇÃO, 26., 2002, Salvador. Anais... Salvador: EnANPAD, 2002. p. 1-16.

MACHADO-DA-SILVA, C. L.; FONSECA, V. S.; FERNANDES, B. H. R. Cognição e institucionalização na dinâmica da mudança em organizações. In: RODRIGUES, S. B.; CUNHA, M. P. (Org.). Estudos organizacionais: novas perspectivas na administração de empresas, uma coletânea luso-brasileira. São Paulo: Iglu, 2000. p. 123-150.

MALHOTRA, N. K. Pesquisa de marketing: uma orientação aplicada. 3. ed. Porto Alegre: Bookman, 2001.

MATSUNO, K.; MENTZER, J. T. The effects of strategy type on the market orientationperformance relationship. Journal of Marketing, v. 64, n. 4, p. 1-16, 2000.

MINAYO, M. O conceito de representações sociais dentro da sociologia clássica. In: JOVCHELOVITCH, S.; GUARESCHI, P. (Org.). Textos em representações sociais. Petróplis, RJ: Vozes, 1997. p. 89-111.

MINTZBERG, H. The strategy concept I: five ps for strategy. California Management Review, v. 30, n. 1, p. 11-24, 1987.
Ascensão e queda do planejamento estratégico. Porto Alegre: Bookman, 2004.

; WATERS, J. A. Of strategies, deliberate and emergent. Strategic Management Journal, v. 6, n. 3, p. 257-272, 1985.

AHLSTRAND, B.; LAMPEL, J. Safári de estratégia: um roteiro pela selva do planejamento estratégico. Porto Alegre: Bookman, 2000.

MINTZBERG, H. et al. O processo da estratégia: conceitos, contextos e casos selecionados. 4. ed. Porto Alegre: Bookman, 2006.

MORGAN, G. Imagens da organização. São Paulo: Atlas, 2000.

MOSCOVICI, S. A representação social da psicanálise. Rio de Janeiro: Zahar, 1978.

Social representation: explorations in social psychology. Cambridge: Polity, 2000.

POIESZ, B. C. The image concept: its place in consumer psychology. Journal of Economic Psychology, v. 10, n. 4, p. 457-472, 1989.

PORTER, M. E. Competitive advantage. New York: Free, 1985.

What is strategy? Harvard Business Review, v. 74, n. 6, p. 61-78, 1996.

Estratégia. In: Expo Management. São Paulo: HSM Management, 2001.

QUINN, J. B. Strategies for change: logical incrementalismo. Homewood: Irwin, 1980.

RODRÍGUEZ, J. J. O. Imágenes mentales. Barcelona: Paidós, 1996.

ROWE, W. G.; BARNES, J. G. Relationship marketing and sustained competitive advantage. Journal of Market Focused Management, v. 2, n. 3, p. 281-297, 1998.

SÁ, C. P. de. Sobre o núcleo central das representações sociais. Petrópolis, RJ: Vozes, 1996.

SAMPAIO, E. F. L. Rastreamento de imagem organizacional na ótica do cliente interno. 1999. Dissertação (Mestrado em Administração) - Escola de Administração, Universidade Federal do Rio Grande do Sul, Porto Alegre, 1998. 
SCHULER, M. Management of the organizational image: a method for organizational image configuration. Corporate Reputation Review, v. 7, n. 1, p. 37-53, 2004.

Management of the organizational image a method for the organizational image configuration. In: PRSA Educator's Academy 2000 Research Conference, 2000.

SENGE, P. M. A quinta disciplina: arte e prática da organização de aprendizagem. São Paulo: Best Seller, 1998.

SONG, M.; PARRY, M. E. A cross-national comparative study of new product development processes: Japan and United States. Journal of Marketing, v. 61, n. 2, p. 1-18, 1997.

THOMPSON Jr., A. A.; STRICKLAND III, A. J. Planejamento estratégico. São Paulo: Pioneira, 2000.

VERGÈS, P. L'evocation de lárgent: une méthode pour la definition du noyau central dune representation. Bulletin de Psychologie, v. 45, n. 405, p. 203-209, 1992.

ZALTMAN, G. Rethinking market research: putting people back. Journal of Marketing Research, v. 34, n. 4, p. 456-472, 1997.

Recebido: 29/07/2007

Received: 07/29/2007

Aprovado: 08/08/2007

Approved: 08/08/2007 